\title{
Tropical connection to the polar stratospheric sudden warming through quasi 16-day planetary wave
}

\author{
C. Vineeth, T. K. Pant, K. K. Kumar, and S. G. Sumod \\ Space Physics Laboratory, Vikram Sarabhai Space Center, Trivandrum-695022, India \\ Received: 14 July 2010 - Revised: 19 August 2010 - Accepted: 29 October 2010 - Published: 5 November 2010
}

\begin{abstract}
The Planetary Waves (PWs) are believed to have significant role in generating the wintertime warming over the polar stratosphere, known as Stratospheric Sudden Warming (SSW). However, the origin, characteristics and evolution of these waves are still speculative. The possibility that the PWs over the polar stratosphere, which play an important role in the generation of SSW, could also have contribution from the tropics has been indicated through many numerical simulations in the past, but due to the paucity of global measurements it could not be established unequivocally. The earlier numerical studies also indicated the presence of a zero-wind line (more general the critical layer, where the zonal wind amplitude becomes zero) whose real counterparts were not observed in the atmosphere. The present study based on the NCEP/NCAR reanalysis of stratospheric wind and temperatures of recent years clearly shows that (i) the zero-wind line appears over the tropics $\sim 60$ days prior to the major SSWs and progresses towards the Pole and (ii) an enhanced PW activity of quasi periodicity 16-days, which is also seen almost simultaneously with the zero-wind line, shows a propagation from equator to the Pole. This result is significant as it presents for the first time the connection between the tropics during the SSW events and the pole, through the quasi 16-day wave.
\end{abstract}

Keywords. Meteorology and atmospheric dynamics (Middle atmosphere dynamics; Polar meteorology; Waves and tides)

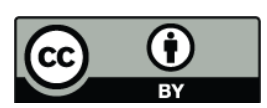

Correspondence to: C. Vineeth (cnvins@gmail.com)

\section{Introduction}

Planetary Waves (PWs) are large-scale perturbations of the atmospheric dynamical structure that extends coherently around a full longitude circle. The perturbations have wavelike form in the longitudinal and vertical directions and often also in the latitudinal direction. These large-scale waves are dominant part of the spatial and temporal variability in the stratosphere, and also make contributions at higher altitudes in the mesosphere (Smith, 2003). The most commonly observed PWs to which the atmosphere readily respond, are of periodicities 2, 5, 10 and 16 days (Salby, 1984; Williams and Avery, 1992). Though, the source region is lower below in the troposphere most of the earlier studies related to the PWs were concentrated on the Mesosphere Lower Thermosphere (MLT) Region. For example, studies performed at MLT heights using the MST-radar data, measured oscillations with periods of 12-19 days (Williams and Avery, 1992). Forbes et al. (1995) have identified the oscillation of period near 16-days from the MF radar at different locations. Similar oscillations have also been reported in the airglow measurements made by Espy and Witt (1996). All of these studies identified the observed waves as the second symmetric, westward propagating, Rossby mode with a zonal wave number 1. Although referred to as the "16-day" or "quasi 16-day" wave, this feature is predicted from theoretical considerations to display periods between 11 and 20 days (Salby, 1981).

Only a few studies about the global structure of the 16-day wave in the mesopause regions have been reported. Forbes et al. (1995) investigated behaviors of the 16-day wave in the mesopause region of the summer hemisphere by using a GSWM (global scale wave model). They showed that the 16-day wave appears in the high-latitude summer hemisphere. However, the wave activity seems to occur most strongly in the winter months (i.e., December to mid-April;

Published by Copernicus Publications on behalf of the European Geosciences Union. 
day numbers $335-110$ where there are typically two or three bursts of activity per year. A second episode of wave activity appears in late summer or autumn, generally occurring between day numbers 200-320 (late July-mid November) (Mitchell et al., 1999). The enhancement of the average amplitude of the wave in the MLT region occurs when the amplitude in the stratosphere becomes large. As of now, it is well realized that the PWs have significant role in modulating various phenomenon right from troposphere to thermosphere.

When it comes to the high latitudes, the phenomenon of Stratospheric Sudden Warming (SSW) is a consequence of the upward propagating PWs from the troposphere and their possible interaction with the Polar Vortex (hereafter PV) (e.g. Matsuno, 1971; Limpasuvan et al., 2004). However, the amplitude of the upward propagating PWs has to be enhanced substantially to initiate the SSW. It is not very clear till today that what causes the PW amplitude to increase rapidly with time, which in turn causes the breaking/displacement of the PV. It has been suggested that the resonance-type instabilities might be responsible for the wave amplification, but it was not very successful in explaining the development of SSWs (Smith, 2003). The stratospheric dynamics also needs to be conditioned so as to be able to carry the waves towards the PV. The appearance of zero wind line is such a preconditioning in the dynamics, which provides an identical refractive index channel that facilitates the reflection of the PWs towards the Pole. The momentum and energy transfer associated with the interactions of PW with PV rapidly increases the polar $\left(>60^{\circ}\right.$ latitude) stratospheric temperatures manifesting as the SSW during the winter months of some particular years. Associated with this poleward increase of temperature $(>25 \mathrm{~K})$, a reversal of zonal-mean stratospheric winds from eastward to westward is also observed. There had been a number of studies over the high latitude regions clearly indicating the dynamical changes prior to the SSW (Matsuno, 1971; Limpasuvan et al., 2004). These changes had been represented as the "preconditioning of the polar stratosphere".

When it comes to the equatorial region, using the stratosphere-mesosphere model Gray et al. (2003a) have shown that the ambient background flow of the stratosphere into which the tropospheric PW propagates depends upon the tropospheric wave forcing and the equatorial wind direction. Similarly they have also modeled the sensitivity of Northern Hemisphere winter stratospheric flow to the equatorial zonal winds in the upper and the lower stratosphere (Gary et al., 2003b). Numerical simulations of Dunkerton et al. (1981) have also shown that there could be a connection between the SSWs and the dynamics over the tropical region $\left( \pm 20^{\circ}\right.$ latitude) in the form of an appearance of a critical layer (or zero-wind line) in wind, first over the tropical stratosphere, and its subsequent movement towards Pole. There had not been enough experimental evidences for such a connection till date. However, some of the recent studies discussing the dynamical changes in the lower atmosphere over the north- ern high latitude regions not only indicate the presence of a zero wind line but also discuss about significance in context of the propagation of PWs (Baldwin and Dunkerton, 1999; Walterscheid et al., 2000; Coughlin and Tung, 2005; Liu and Roble, 2005).

In this context, the global reanalysis data of recent years, provided by the National Centers for Environmental Prediction (NCEP) and National Center for Atmospheric Research (NCAR) have been found to be useful to investigate processes, which are global and large-scale in nature due to a better coverage of actual observations and modeling database (Kalnay et al., 1996). It is assumed that the NCEP/NCAR reanalysis data would reproduce the large-scale dynamical changes and the PWs well, whenever they are present. In fact, the NCEP/NCAR reanalysis data has been used by many researchers to study the evolution of the PWs and the SSWs over the Northern Hemisphere (Chen et al., 2003; Limpasuvan et al., 2004; Li et al., 2007; Pancheva et al., 2008). In a recent study, Vineeth et al. (2009) have suggested that during the SSW year there could be a propagation of quasi 16-day wave disturbance from equatorial stratosphere to North Pole in about a month, which is more or less, aligned with the stratospheric zero wind line. However they have used only one SSW case to arrive at this conclusion. Therefore in the present investigation, analysis of some additional database has been carried out using the NCEP/NCAR reanalysis on stratospheric wind and temperature. To be more precise, in this paper we present comparative case studies (more than one) from one database, primarily to investigate (i) whether a real counterpart of the critical layer (zero wind line), as inferred through the simulations, exists in the atmosphere during the SSW (ii) whether there is any systematic trend in the PW activity over different latitudes, which could be indicative of a possible coupling between the tropics and the Pole and (iii) has the phase of the QBO play any role in such coupling. Our analysis indeed reveals a clear cut "preconditioning" in the stratosphere over the tropics, much prior to the SSW i.e. about $\sim 60$ days. It is found to be manifesting as the appearance of the "zero-wind line" at the $10 \mathrm{hPa}$ level $(\sim 30 \mathrm{~km})$ and moving poleward, a feature similar to one described by Dunkerton et al. (1981). The paper discusses these aspects in detail.

\section{Database}

The daily mean global stratospheric wind and temperature data at $10-\mathrm{hPa}(\sim 30 \mathrm{~km})$ level obtained from NCEP/NCAR reanalysis during the period September-March for three SSW years (2003-2004), (2005-2006), (2007-2008) and for a non-SSW year (2004-2005) are used in the study. It must be mentioned that the SSWs occurred during (2003-2004) and (2005-2006) were major SSWs and the SSW of the year (2007-2008) was a minor one. Though it was a minor SSW, the SSW of the year (2007-2008) was associated with a sharp 
change in the zonal wind direction. Since the present paper analyses the behavior of the features, which extends on a global scale, the latitude resolution has been considered as $10^{\circ}$. Therefore, the data at every $10^{\circ}$ latitude from equator to North Pole are used for representing the global circulation changes and the evolution of the quasi 16-day wave. The zonal-mean zonal wind (daily mean) for the aforementioned latitudes has been used to study the behavior of the zero-wind line. For the present study the raw data are used and no smoothing has been applied to any of the data set. It must be mentioned that, $10 \mathrm{hPa}$ level is in the brim of the NCEP/NCAR reanalysis data and there could be some uncertainties because of this. However, since we are not comparing the actual magnitudes of any parameters and only interested in the large-scale features, this is not believed to be a serious issue. As mentioned earlier, the number of actual measurements used for the NCEP/NCAR reanalysis data has increased substantially during the recent years. Therefore the present study has been restricted to investigate about the recent SSWs only.

\section{Observations}

The NCEP/NCAR Stratospheric Temperatures (ST) at $10 \mathrm{hPa}$ level $(\sim 30 \mathrm{~km})$ and every $10^{\circ}$ latitude from equator to North Pole over the Indian longitudes i.e. $77^{\circ} \mathrm{E}$ during September-March period for the SSW years (2003-2004), (2005-2006) and (2007-2008), and a non-SSW year (20042005) were analyzed. Figure 1 depicts the zonal mean Polar Stratospheric Temperature (PST) at $10 \mathrm{hPa}$ level over $80^{\circ} \mathrm{N}$ latitude for the considered years of study, for highlighting the occurrence of the SSW. The day number 1 labeled in the figures corresponds to 1 September. The major SSW occurred around day number 130 during the year (2003-2004) and around day number 144 during (2005-2006) and a minor SSW around day number 147 during (2007-2008) (dotted lines represent the day of maximum warming and wave propagation is highlighted using the arrows in Fig. 2). Further, the PST in all the years show large-scale oscillations $(>10$ days). In order to find out the nature of this oscillation, the time series data at every $10^{\circ}$ latitude from equator to North Pole latitudes were subjected to wavelet analysis using the Morlet wavelet as the mother wavelet (Torrence and Compo, 1998). Among different mother wavelets, it has been shown that the Morlet wavelet is more reliable for dealing the geophysical parameters compared to the others (Liu et al., 2007). The wavelet analysis revealed the presence of a quasi 16-day wave as the dominant planetary wave. The time evolutions of this wave at each latitude region were then used to construct the time-latitude structure of the wave activity. The amplitudes were normalized according to their maximum values at each latitude. This was done because of the fact that the amplitude of the PW is much higher at high latitudes in comparison with that of the low latitudes. Therefore, in order to

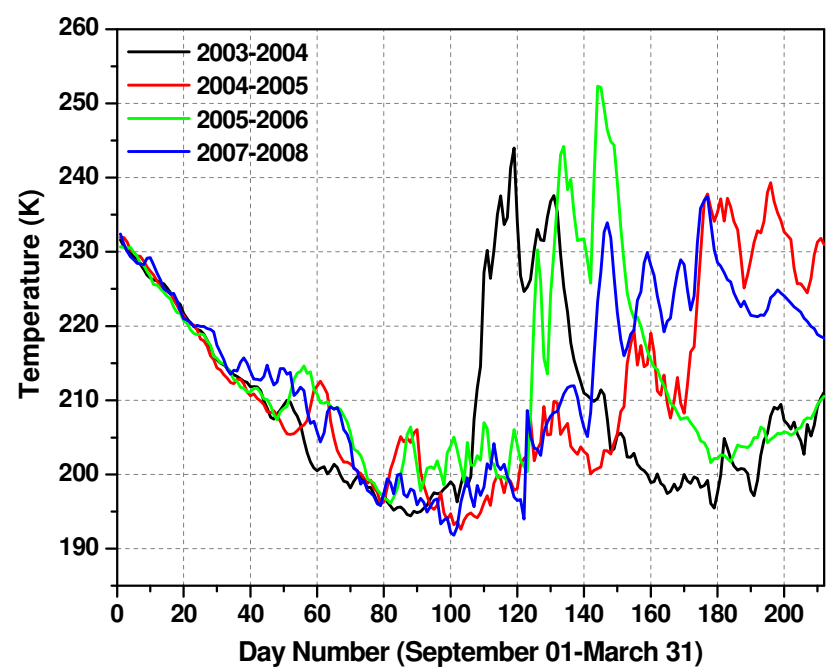

Fig. 1. Daily variation of daymean Polar Stratospheric Temperature (at $10 \mathrm{hPa}$ ) during the SSW years (2003-2004), (2005-2006) (2007-2008) and (non-SSW year (2004-2005).

highlight the variability of the wave at low and mid latitudes the amplitudes were normalized. The time-latitude structures of quasi 16-day waves with normalized amplitudes thus obtained for the SSW years are depicted in Fig. 2a, c and d. The red and blue patches in the figures correspond to the crest and trough of the quasi 16-day wave, respectively.

It is very exciting to note from Fig. 2 that, during the SSW years the presence of the quasi 16-day wave in ST appears to be gradually advancing towards pole from the tropics. For the SSW of (2005-2006), the wave takes $\sim 60$ days to reach the high latitudes $\left(>60^{\circ}\right)$ and the first minor warming is coincident with time when the PW modulations appear there (day number 127), the second minor and major warmings (day number 144 - dotted line in Fig. 2a) occurred subsequently. During the SSW of (2003-2004), the wave takes $\sim 65$ days to reach the Pole and the major SSW is observed around day number 130 . On the other hand, during the year (20072008) the wave has propagated from equator to Pole within $\sim 55$ days. Figure $2 d$ represents the time latitude evolution of the quasi 16-day wave during a non-SSW year (20042005). The systematic progression of the PW from tropics to the Pole as observed during the SSW years is not observed during the non-SSW year (Fig. 2b). In fact, the PWs appear to have dominated nearly all the latitude regions during this year. As is conspicuous from the figure, the PW activity over the tropics get intensified just after the equinox i.e. 21 September (day number 21). However, the propagation to the Pole begins only after 10 November (day number 70 ) for all the SSW years.

Figure 3 shows the variations of the zonal mean zonal wind at $10 \mathrm{hPa}$ for the SSW years and the non SSW year discussed above. It is seen that for all the SSW years a combination of low wind and zero-wind regime, appears at about $10^{\circ} \mathrm{N}$ 

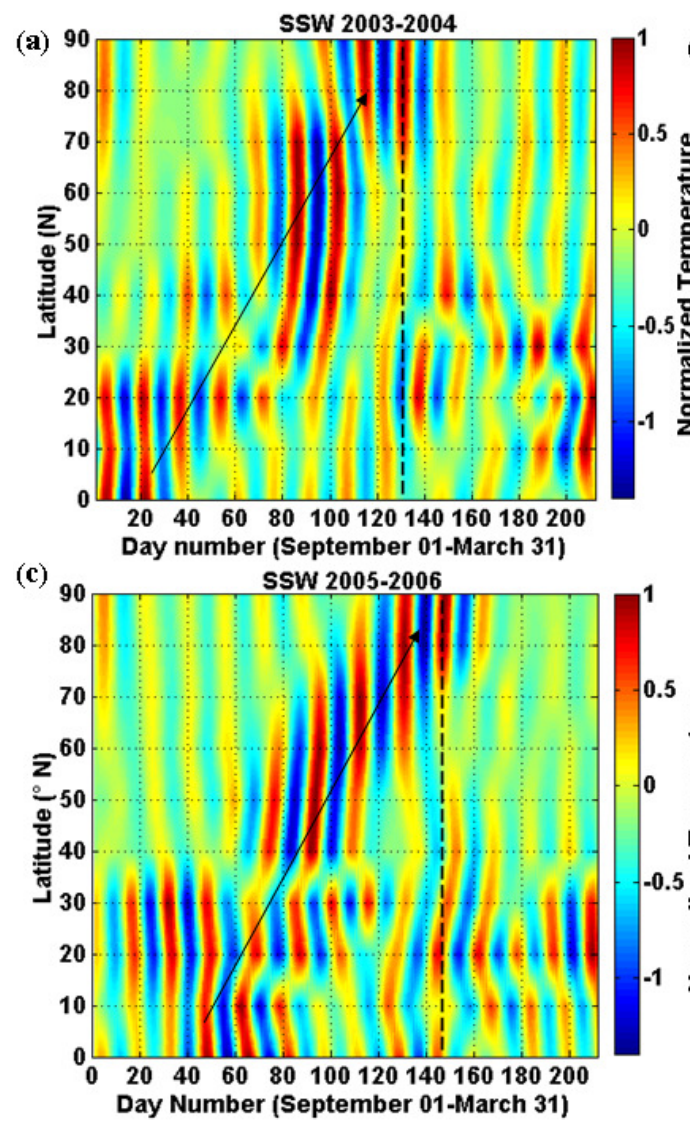
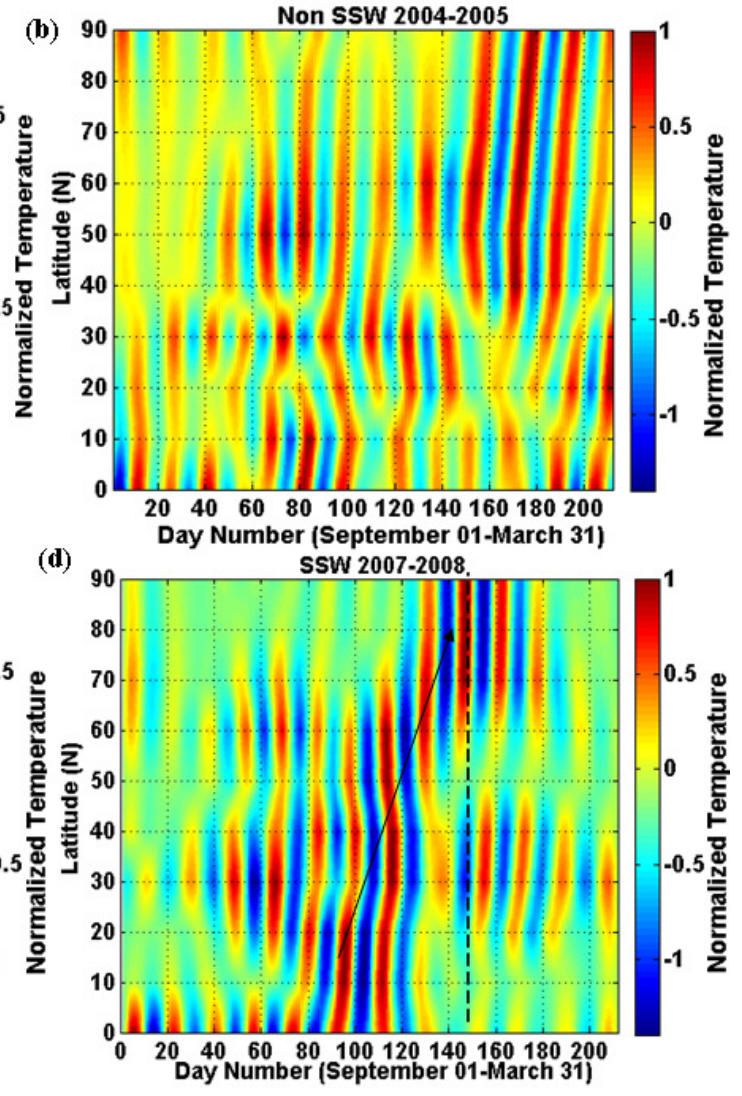

Fig. 2. The evolution of quasi 16-day wave from equator to North Pole during SSW years of (a) 2003-2004, (c) 2005-2006 (d) 2003-2004 and non SSW year (b) 2003-2004. The day of occurrence of the major SSW is marked in each figure as dotted lines.

around day number 70 (day number 90 in case the year 2007 2008 ), which then gradually moves poleward, reaching $60^{\circ} \mathrm{N}$ around day number 140 in the case of the SSW (2005-2006), day number 120 in case of SSW (2003-2004) and day number 147 in case of SSW (2007-2008). Since it is relatively difficult to find out the zero wind line from the colorbar we have added the zero wind line separately to the figures (blue line in Fig. 3) by noting down the day number corresponding to each latitude where the wind showed the transition. This corroborates with the propagation of the PW as mentioned in Fig. 2. Nevertheless, the appearance of zero wind regimes near tropics and its progression towards the Poles is also absent during the non-SSW year (Fig. 3b). Further, during the SSW years, the appearance and the progression of the zero-wind line over the tropics is nearly coincident in time with the ongoing large-scale changes in the zonal-mean zonal wind over the polar latitudes. During non-SSW year, such simultaneous variability is not observed.

From Fig. 3 it is evident that during the SSW years the wind over the equator is more or less eastward and during non-SSW year westward. This is attributed to the prevailing phase of the stratospheric Quasi Biennial Oscillation (QBO) which is opposite in these two years. The QBO is a regu- lar equatorial phenomenon of 2 to 3 year cycle characterized by alternating descending regimes of westward and eastward zonal wind (Baldwin et al., 2001). Holton and Tan (1982) have indicated that during the westerly (easterly) phase of the equatorial QBO the polar night jet is stronger (weaker) than normal and the tropospheric mid-latitude jet is slightly weaker (stronger) than normal. They have also suggested a possible link between the equatorial QBO and the extra tropical circulation through vertically and meridionally propagating stationary PWs in the winter hemisphere. The amplitudes and phases of such waves should depend rather sensitively on the latitudinal position of the critical surface along which the mean zonal wind vanishes. From the above studies, it is clear that the QBO plays an important role as far as the formation of the zero wind line and the propagation of the PWs are concerned. Since the considered years of the present study represent consecutive years (except the year 2007-2008), which can very well represent the features of the QBO. 
(a)

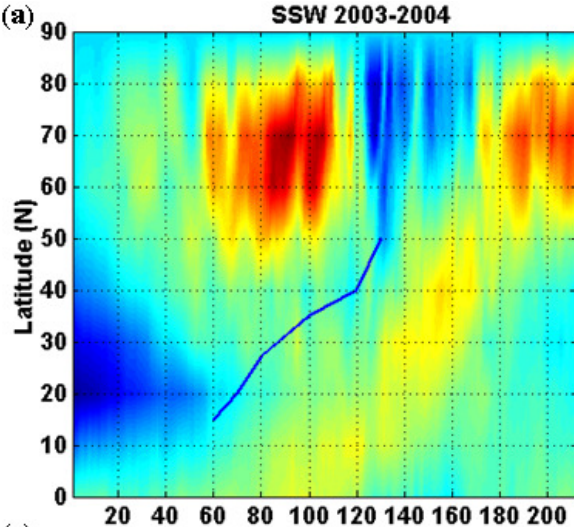

(c)
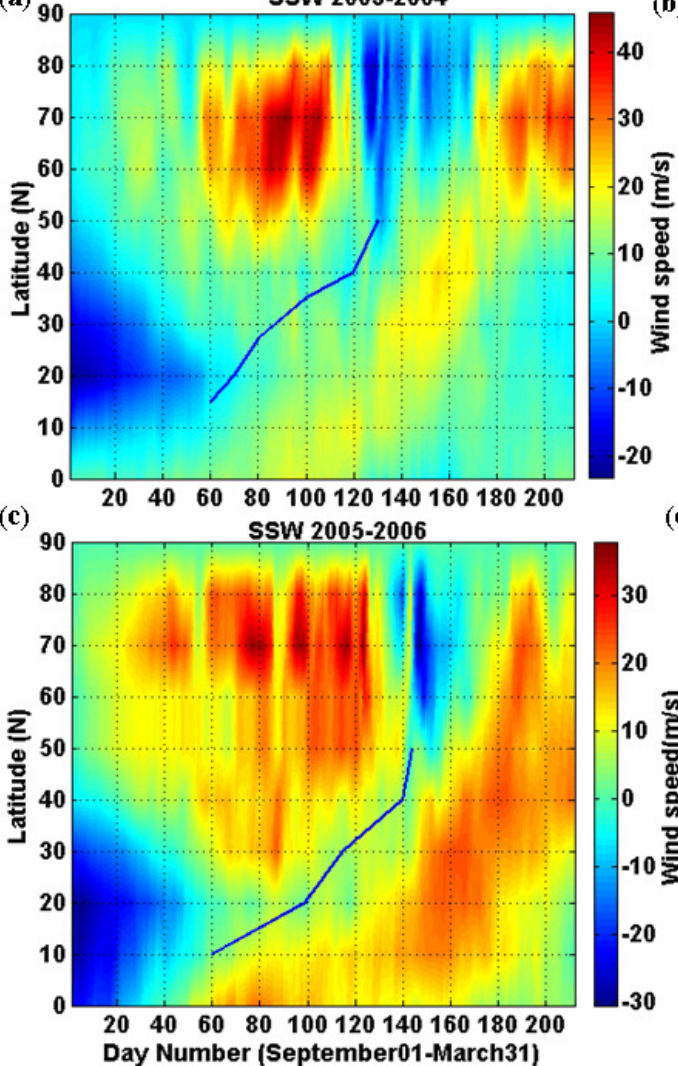

(b)

(d)

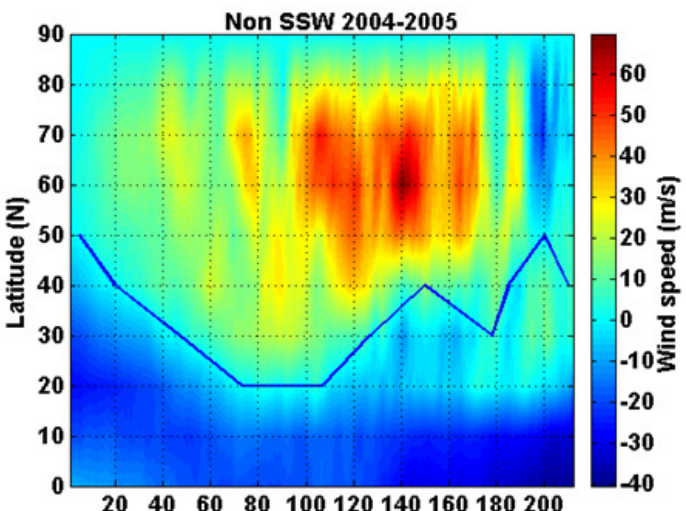

SSW 2007-2008

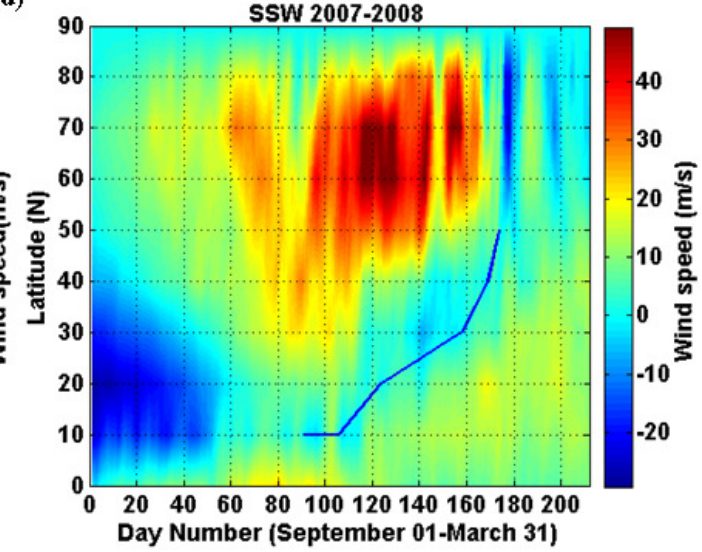

Fig. 3. The time variation of the zonal-mean zonal wind from equator to North Pole during the SSW years of (a) 2003-2004, (c) 2005-2006 (d) 2003-2004 and non SSW year (b) 2003-2004. The zero wind line is plotted in each figure as the blue line.

\section{Results and discussions}

In a recent study, using the NCEP/NCAR data and the TIMEGCM, the dynamical changes in the mesosphere and the stratosphere were analyzed for the Southern Hemisphere SSW event of 2002 and a strong feedback taking place between the PWs and the mean dynamics of the mesosphere and stratosphere was shown (Liu and Roble, 2005). This study indicated that the PW surf zone descends from the mesospheric to the stratospheric altitudes in the preconditioning phase of the SSW. When the surf zone reaches stratosphere and the zero-wind line line (critical layer) appears at these altitudes, the SSW occurs. The mesospheric/stratospheric dynamical conditions, which influence the PW transmission and breaking, have been shown to change at least $\sim 60$ days before the major warming. In fact, it was first shown through numerical simulations that during the SSW years the global circulation exhibits significant variations in the form of a poleward advancing zero wind line in the zonal mean zonal wind (Dunkerton, 1981). Similarly, Gray et al. (2003b) have shown that stratospheric flow in the Northern Hemisphere winter is sensitive to the equatorial zonal winds in the upper and the lower stratosphere.
In recent years, a number of studies have emerged which show that these changes in stratospheric circulation do not remain static over stratospheric altitudes but continue to descend further down affecting the tropospheric circulation (Baldwin and Dunkerton, 1999, 2001; Limpasuvan et al., 2004; Coughlin and Tung, 2005). The influence of stratospheric circulation on the troposphere has been found to persist for up to two months. In this context, the importance of the dynamics, as well as the zero-wind line, has already been clearly highlighted over the polar latitudes. Though there are no evidences of the same over tropical latitudes, it was shown through simulations that the mid stratospheric zero wind invades the middle latitudes from tropics during the evolution of the SSW (Dunkerton, 1981). The present analysis clearly shows that during the SSW years the stratospheric zero wind line indeed gets formed over the tropics, which progresses towards the North Pole with time. The near simultaneity in the variability of the stratospheric wind prior to the SSW over high latitudes and the appearance and progression of the zero-wind line and the quasi 16-day wave over the tropics indicate that these two latitude regions are indeed dynamically linked. It must be mentioned that, the critical layer is not necessarily formed at the zero wind regime and it could 
be formed in the low-wind regime too. However, the above conclusion is arrived by using the data from a single level (i.e. at $10 \mathrm{hPa}$ ) and there may be limitation because of this.

Researchers in the past have reported the interannual variability of the quasi 16-day wave (Espy et al., 1997; Jacobi et al., 1998) using the nighttime $\mathrm{OH}$ temperatures during day numbers 170-235 (June-August) of 1992-1995 over a mid latitude station, Stockholm $\left(59.5^{\circ} \mathrm{N}\right)$ and have identified the signature of the quasi 16-day wave in 1992 and 1994, but not 1993 or 1995 . The authors attributed this phenomenon to the westward phase of the QBO blocking the cross-equator propagation of the wave from a source in the winter hemisphere. In other words, supporting the idea that the wave observed in the summer hemisphere has propagated across the equator from the winter hemisphere rather than being excited in situ (Forbes et al., 1995; Espy et al., 1997). In more comprehensive study, Holton and Tan $(1980,1982)$ have shown the influence QBO to the global circulations. However, it should be noted that in the modeling study of Forbes et al. (1995), the cross-equator propagation pathway was found to be at mesopause heights and so would be largely unaffected the influence of the stratospheric QBO. The present study indeed shows that this cross equatorial pathway could be found as low as stratospheric altitudes $(\sim 30 \mathrm{~km})$ during the eastward phase of the QBO and absent during the westward phase.

Further, the time taken by the zero-wind line in progressing from tropics to the latitudes exhibiting the SSW is $\sim 60$ days, which corroborates with Liu and Roble (2005) where a long preconditioning time of about $\sim 60$ days was observed. In fact, they showed that about 60 days prior to the major SSW, significant increase in the PW activity occurs over the high latitudes. It is realized that the presence of zero-wind line at any latitude will have significant implications in the propagation of the wave through the stratosphere over that latitude region. The presence of the zero wind line provides an identical refractive index channel, which facilitates the reflection of the PWs towards the Pole. During the SSW, large negative zonal-mean zonal wind anomalies had been found poleward of $50^{\circ} \mathrm{N}$ in the stratosphere, showing that in the PV displacements, anomalous wave activity begins $\sim 20$ days before winds in the stratosphere become easterly (Charlton and Polvani, 2007). This observation is consistent with Holton's (1980) numerical simulation of poleward advancing critical levels from the equatorial regions. Earlier investigations have shown that the momentum fluxes associated with the waves during the SSW switches from upward and equatorward to upward and poleward through the feedback effect of an evolving mean flow over the wave propagation (O'Neill and Youngblut, 1982; Karoly and Hoskins, 1982). In this context, the observation of the PW modulations over the tropics almost simultaneous with the zero-wind line and the subsequent progression of these modulations towards pole somewhat corroborate with these results. However, looking at only one level $(10 \mathrm{hPa})$ would not be enough to unequivocally demonstrate the presented observation, es- pecially the exact altitude region where the zero wind regime forms and the wave-mean flow interaction occurs. Therefore, extensive studies are called for, which involves the analysis of the data at various levels to understand these aspects better.

\section{Conclusion}

The low latitude-high latitude coupling during the polar SSW is established through (a) simultaneous appearance of stratospheric zero-wind line and a planetary wave of quasi 16-day periodicity and (b) both propagating from equator to North Pole. The background circulation in the stratosphere, especially the phase of the QBO is believed to have a significant bearing on this; however the exact mechanism involved therein remains to be indistinguishable. Nonetheless, the results presented here are significant as they bring out a hitherto unnoticed aspect of the stratospheric dynamics and the PWs over tropics, which appear to have relevance in context of the SSW. The study also highlights the need for a better understanding of the "coupling processes" involving in various atmospheric regions over the globe, especially over the tropics.

Acknowledgements. This work was supported by Department of Space, Government of India. One of the authors C. Vineeth gratefully acknowledges the financial assistance provided by the Indian Space Research Organization. C.V. acknowledges Mark Baldwin from North West Research Associates, Bellevue, WA, USA, for valuable discussions.

Topical Editor C. Jacobi thanks one anonymous referee for her/his help in evaluating this paper.

\section{References}

Andrews, D. G., Holton, J. R., and Leovy, C. B.: Middle Atmosphere Dynamics, Academic Press, Inc, Chapter 6, 259, 1987.

Baldwin, M. P. and Dunkerton, T. J.: Propagation of the Arctic Oscillation from the stratosphere to the troposphere, J. Geophys. Res., 104(D24), 30937-30946, 1999.

Baldwin, M. P., Gray, L. J., Dunkerton, T. J., et al.: The quasibiennial oscillation, Rev. Geiophys., 39, 179-229, 2001.

Charlton, A. J. and Polvani, L. M.: A New Look at Stratospheric Sudden Warmings. Part I: Climatology and Modeling Benchmarks, J. Climate, 20, 449-469, 2007.

Chen, W., Graf, H. F., and Takahashi, M.: Observed interannual oscillations of planetary wave forcing in the Northern Hemisphere winter, 29, 2073, doi:10.1029/2002GL016062, 2002.

Coughlin, K. and Tung, K. K.: Tropospheric wave response to decelerated stratosphere seen as downward propagation in northern annular mode, J. Geophys. Res., 110, D01103, doi:10.1029/2004JD004661, 2005.

Dunkerton, T. J., Hsu, C. P. F., and McIntyre, M. E.: Some Eulerian and Lagrangian diagnostics for a model stratospheric warming, J. Atmos. Sci., 38, 819-843, 1981.

Espy, P. J., Stregmann, J., and Witt, G.: Interannual variation of the quasi-16-day oscillation in the polar summer mesospheric temperature, J. Geophys. Res., 102(2), 1983-1990, 1997. 
Espy, P. J. and Witt, G.: Observation of a quasi 16-day oscillation in the polar summer mesospheric temperature, Geophys. Res. Lett., 23(10), 1071-1074, doi:10.1029/96GL01068, 1996.

Forbes, J. M., Hagan, M. E., Miyahara, S., et al.: Quasi 16-day oscillation in the mesosphere and lower thermosphere, J. Geophys. Res., 100, 9149-9163, 1995.

Gray, L. J.: The influence of the equatorial upper stratosphere on stratospheric sudden warmings, Geophys. Res. Lett., 30(4), 1166, doi:10.1029/2002GL016430, 2003.

Gray, L. J., Sparrow, S., Juckes, M., O'Neill, A., and Andrews, D. G.: Flow regimes in the winter Stratosphere of the northern hemisphere, Q. J. Roy. Meteorol. Soc., 129, 925-945, 2003.

Holton, J. R.: The dynamics of sudden stratospheric warmings, Ann. Rev. Earth Planet. Sci., 8, 169-190, 1980.

Holton, J. R. and Tan, H. C.: The quasi-biennial oscillation in the Northern Hemisphere lower stratosphere, J. Meteorol. Soc. Jpn., 60, 140-148, 1982.

Holton, J. R. and Tan, H. C.: The influence of the equatorial Quasi-Biennial Oscillation on the global atmospheric circulation at $50 \mathrm{mb}$, J. Atmos. Sci., 37, 2200-2208, 1980.

Jacobi, C., Schminder, R., and Kuerschner, D.: Planetary wave activity obtained from long-period (2-18 days) variations of mesopause region winds over Central Europe $\left(52^{\circ} \mathrm{N}, 15^{\circ} \mathrm{E}\right), \mathrm{J}$. Atmos. Solar-Terr. Phys., 60, 81-93, 1998.

Kalnay, E., Kanamitsu, M., Kistler, R., et al.: The NCEP/NCAR 40Year Reanalysis Project, B. Am. Meteorol. Soc., 77, 437-471, 1996.

Karoly, D. J. and Hoskins, B. J.: 3 dimensional propagation of planetary-waves, J. Meteorol. Soc. Jpn., 60, 109-123, 1982.

Labitzke, K.: Stratospheric-mesospheric midwinter disturbances: A summary of observed characteristics, J. Geophys. Res., 86, 9665-9678, 1981.

Li, Q., Graf, H.-F., and Giorgetta, M. A.: Stationary planetary wave propagation in Northern Hemisphere winter - climatological analysis of the refractive index, Atmos. Chem. Phys., 7, 183200, doi:10.5194/acp-7-183-2007, 2007.

Limpasuvan, V., Thompson, D. W. J., and Hartmann, D. L.: The Life Cycle of the Northern Hemisphere Sudden Stratospheric Warmings, J.Climate, 17, 2584-2596, 2004.

Liu, H. L. and Roble, R. G.: Dynamical coupling of the stratosphere and mesosphere in the 2002 Southern Hemisphere major stratospheric sudden warming, Geophys. Res. Lett., 32, L13804, doi:10.1029/2005GL022939, 2005.
Liu, Y., San Liang, X., and Weisberg, R. H.: Rectification of the Bias in the Wavelet Power Spectrum, J. Atmos. Ocean Tech., 24, 2903-2102, 2007.

Matsuno, T.: A dynamical model of the stratospheric sudden warming, J. Atmos. Sci., 28, 1479-1494, 1971.

Mitchell, N. J., Middleton, H. R., Beard, A. G., Williams, P. J. S., and Muller, H. G.: The 16-day planetary wave in the mesosphere and lower thermosphere, Ann. Geophys., 17, 1447-1456, doi:10.1007/s00585-999-1447-9, 1999.

O'Neill, A. and Youngblut, C. E.: Stratospheric warming diagnosed using the transformed Eulerian-mean equations and the effect of mean state on wave propagation, J. Atmos. Sci., 39, 1370-1386, 1982.

Pancheva, D. V., Mukhtarov, P. J., Mitchell, N. J., et al.: Planetary wave coupling (5-6-day waves) in the low-latitude atmosphereionosphere system, J. Atmos. Solar Terr. Phys., 70, 101-122, 2008.

Salby, M. L.: Rossby normal modes in non-uniform background configurations, I: simple fields, J. Atmos. Sci., 38, 1803-1826, 1981.

Salby, M. L.: Survey of planetary-scale travelling waves: the state of theory and observations, Rev. Geophys. Space Phys., 22(2), 209-236, 1984.

Schoeberl, M. R. and Strobel, D. F.: Numerical simulation of the Sudden Stratospheric Warmings, J. Atmos. Sci., 37, 214-236, 1979.

Smith, A. K.: Planetary Waves, Encyclopedia of the Atmos. Sci., Academic Press, 3, 1314, 2003.

Torrence, C. and Compo, G. P.: A practical guide to Wavelet analysis, B. Am. Meteorol. Soc., 79, 61-78, 1998.

Vineeth, C., Pant, T. K., Kumar, K. K., Ramkumar, G., and Sridharan, R.: Signatures of low latitude-high latitude coupling in the tropical MLT region during sudden stratospheric warming, Geophys. Res. Lett., 36, L20104, doi:10.1029/2009GL040375, 2009.

Walterscheid, R. L., Sivjee, G. G., and Roble, R. G.: Mesospheric and lower thermospheric manifestations of a stratospheric warming event over Eureka, Canada $\left(80^{\circ} \mathrm{N}\right)$, Geophys. Res. Lett., 28, 2897-2900, 2000.

Williams, C. R. and Avery, S. K.: Analysis of long-period waves using the mesosphere-stratosphere-troposphere radar at Poker Flat, Alaska, J. Geophys. Res., 97, 20855-20861, 1992. 